\title{
Interventional cardiology in Switzerland during the year 2010
}

Micha T. Maeder, Giovanni Pedrazzini, Marco Roffi, Christoph A. Kaiser, Stéphane Cook, Roberto Corti, Peter Wenaweser, Hans Rickli

On behalf of the Swiss Working Group on "Interventional Cardiology and Acute Coronary Syndrome"

\section{Summary}

Background: Since 1987, a nationwide annual survey of percutaneous cardiac interventions has been performed in Switzerland to assess trends in endovascular cardiac procedures.

Methods: The volume and type of endovascular cardiac procedures performed during the year 2010 were collected by means of a standardised questionnaire from all adult cardiac intervention centres in Switzerland.

Results: The number of coronary angiographies (2010: $\mathrm{n}=42648 ;+2.5 \%$ compared to 2009 ) and percutaneous coronary interventions $(n=19925$; $+4.7 \%)$ continued to increase with a slight increase in the PCI/CA ratio (46.7\%; 2009: 45.7\%). After a decrease from 2006 to 2007 and a plateau from 2007 to 2009, the proportion of drug-eluting stents (DES) raised again to $79 \%$ in 2010 (2009: 72\%). Apart from shunt closures which remained stable (closure of patent foramen ovale [ $\mathrm{n}=$ 733; 2009: $\mathrm{n}=728$ ] and atrial septal defects $[\mathrm{n}=142$; 2009: $\mathrm{n}=152]$ ), the number of procedures for structural heart disease increased in 2010 mainly due to an increasing number of transcatheter aortic valve implantations $(\mathrm{n}=382$ performed in 11 centres; 2009 : $\mathrm{n}=$ 277 performed in 8 centres) although the number of procedures for transcatheter mitral valve repair rose as well ( $\mathrm{n}=67 ; 2009: \mathrm{n}=33)$.

Conclusions: The number of both CA and PCI procedures increased in Switzerland in 2010 compared with the previous year. However, the most expanding segment of percutaneous cardiac intervention involved those for structural heart disease, namely TAVI.

Key words: coronary angiography; angioplasty; stents, patent foramen ovale; transcatheter aortic valve implantation

\section{Introduction}

Funding / potential competing interests: No financial support and no other potential conflict of interest relevant to this article were reported
Since 1987, a nationwide survey of interventional procedures in all Swiss cardiology centres has been performed annually $[1,2]$ to asses trends in percutaneous cardiac procedures. This allows for compari- sons with other countries and offers insights into the practice of interventional cardiology in Switzerland. In particular, the survey allows for monitoring of novel techniques such as transcatheter aortic valve implantation (TAVI) and transcatheter mitral valve repair (TMVR).

\section{Methods}

Based on a standardised questionnaire, detailed in the 2007 report [3], all cardiology centres performing interventional procedures in adult patients were asked to report the number and type of procedures performed in 2010. All centres participating in the 2009 survey also contributed data for 2010, although for some centres information was not available for all items. Complications were only reported by a minority of centres. Given the lack of a standardised data collection on complications, this information is not reported due to the lack of reliability. For a better understanding of trends, the 2010 results are reported in the context of the data over last five years.

\section{Results}

\section{Structure of Swiss centres}

In 2010 , there were 29 active interventional cardiology centres (6 university [new university hospital centre: Fribourg], 10 public, non-university, 13 private institutions) in Switzerland, all of which performed both diagnostic procedures and percutaneous cardiac interventions. As in 2009, the Hirslandenkliniken in Zürich (previously Klinik Im Park, Klinik Hirslanden Zürich) as well as the University Hospital Zürich (UniversitätsSpital Zürich [USZ]), the Kantonsspital Winter-

Correspondence:

Micha T. Maeder, MD

Division of Cardiology

Department of Internal Medicine

Rorschacherstrasse 95

CH-9007 St. Gallen

Switzerland

micha.maeder[at]kssg.ch 
thur (KSW) and the Spital Thurgau AG (Frauenfeld $[\mathrm{FF}])$ reported pooled data, and the hospitals were considered as one single centre each. In 2010, the Inselspital and the Sonnenhofklinik also reported pooled data

\section{Figure 1}

Numbers of coronary angiographies (CA) and percutaneous coronary interventions (PCI) from 2006 to 2010 in Switzerland.

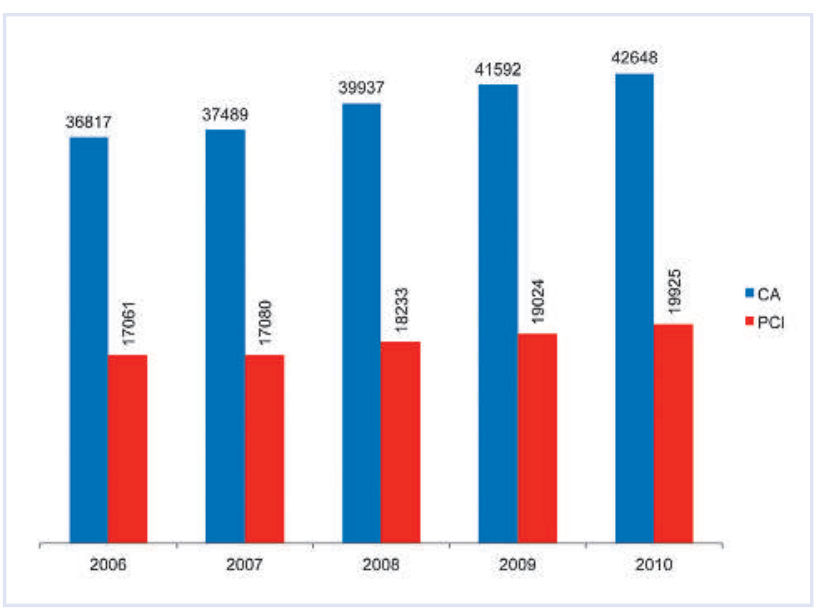

\section{Figure 2}

Coronary angiographies (CA) and percutaneous coronary interventions $(\mathrm{PCI})$ in all centres during the year 2010. The centres are ranked according to their annual CA volume.

USZ = UniversitätsSpital Zürich, KSW = Kantonsspital Winterthur, FF = Spital AG Thurgau (Frauenfeld)

*CA: Hirslanden: 1512, Im Park: 1702; PCI: Hirslanden: 511, Im Park: 774 \#CA: USZ: 2575, KSW: 646, FF: 218; PCI: USZ: 1137, KSW: 301, FF: 88. tCA: Inselspital: 4859, Sonnenhof: 692; PCI: Inselspital: 2273, Sonnenhof: 348.

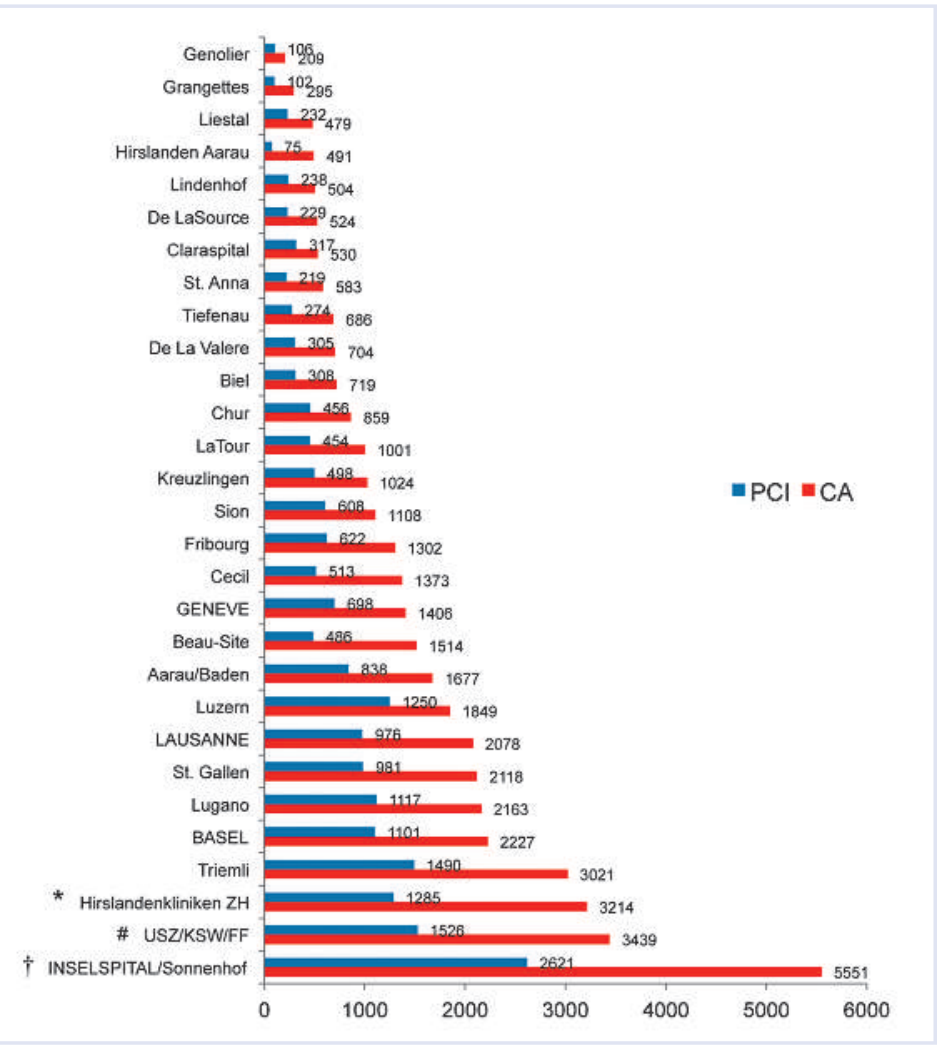

and were considered one single centre. A total of 16 centres had one laboratory, 9 centres had two, one centre had three, one centre had four laboratories, and two centres had five laboratories. In 2010, 58 operators performed coronary angiography (CA) only, and 144 operators performed both $\mathrm{CA}$ and percutaneous coronary interventions (PCI). In 15 centres (52\%), cardiac surgery was available on site.

\section{Coronary interventions}

In 2010, $42648 \mathrm{CA}$ (2009: 41592; +2.5\%) and 19925 PCI (2009: 19024; +4.7\%) were performed in Switzerland. As shown in figure 1, there was a steadily increasing number of both CA and PCI from 2006 to 2010. The PCI/CA ratio increased slightly to $46.7 \%$ in 2010 (45.7\% between 2007 and 2009). PCI was performed ad hoc in the majority of cases (88\%; data not available from two centres; 2009: 89\%). The majority of PCI procedures constituted single-vessel interventions (77\%; data not available from one centre; 2009: 80\%).

Figure 2 displays the distribution of CA and PCI among the different centres in 2010. The average number of CA and PCI per operator was 211 (2009: 230) and 138 (2009: 136) respectively, resulting in 26.7 CA operators per million inhabitants and 17.5 PCI operators per million inhabitants. The average number of PCI per operator was 164 (2009: 184) in university hospitals, 176 (2009: 164) in public non-university hospitals, and 84 (2009: 84) in private hospitals.

\section{Coronary stents}

The stent utilisation rate in 2010 was 91\% (data not available from one centre; 2009: 90\%). In 41\% of PCI, two or more stents were implanted (data not available from two centres; 2009: 41\%). With 79\% of all stents, drug-eluting stents (DES) constituted the most frequently applied stent type. As shown in figure 3 , the

\section{Figure 3}

Evolution of the use of drug-eluting stents between 2006 and 2010. The bars represent the drug-eluting stent utilisation rates (percutaneous coronary interventions [PCI] with drug-eluting stent placement / all $\mathrm{PCl}$ with stent implantation).

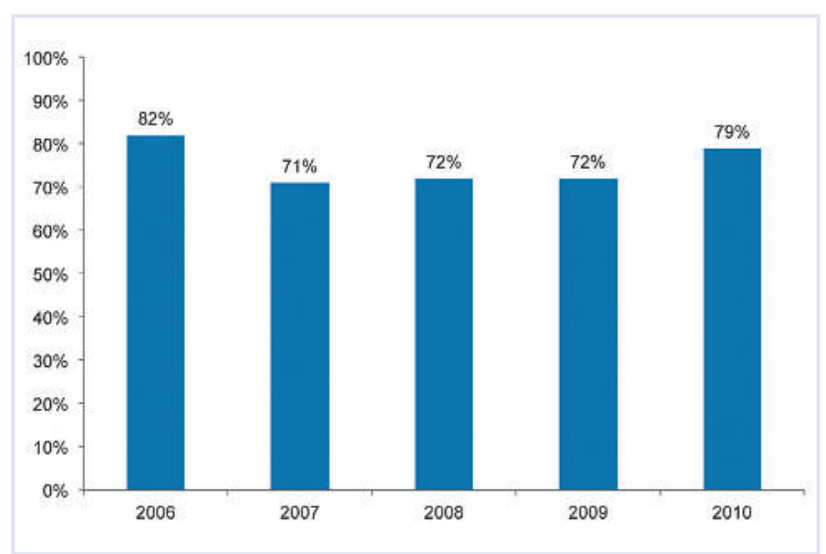


Figure 4

Use of glycoprotein Ilbllla inhibitors between 2006 and 2010 (percutaneous coronary interventions [PCI] with use of glycoprotein Ilbllla inhibitors / all PCI).

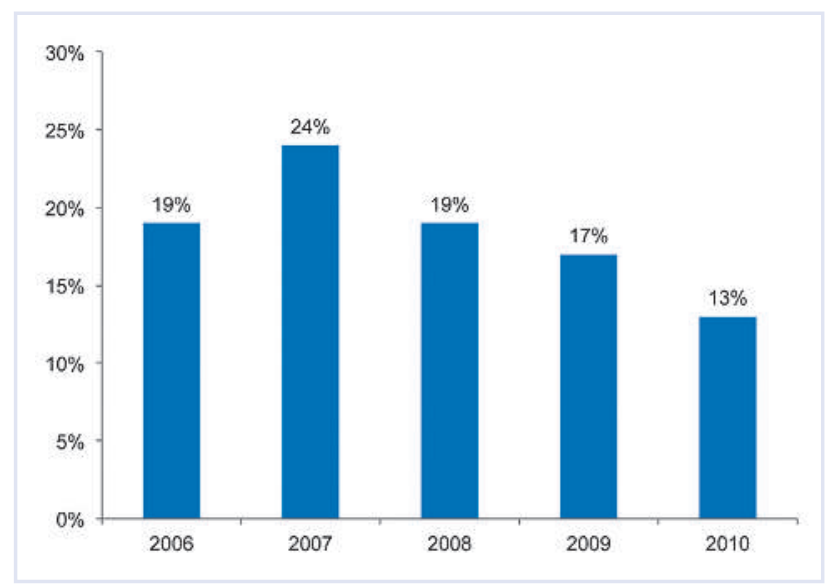

\section{Figure 5}

Balloon valvuloplasties from 2006 to 2010. The figure does not include transcatheter aortic valve implantation and transcatheter mitral valve repair procedures.

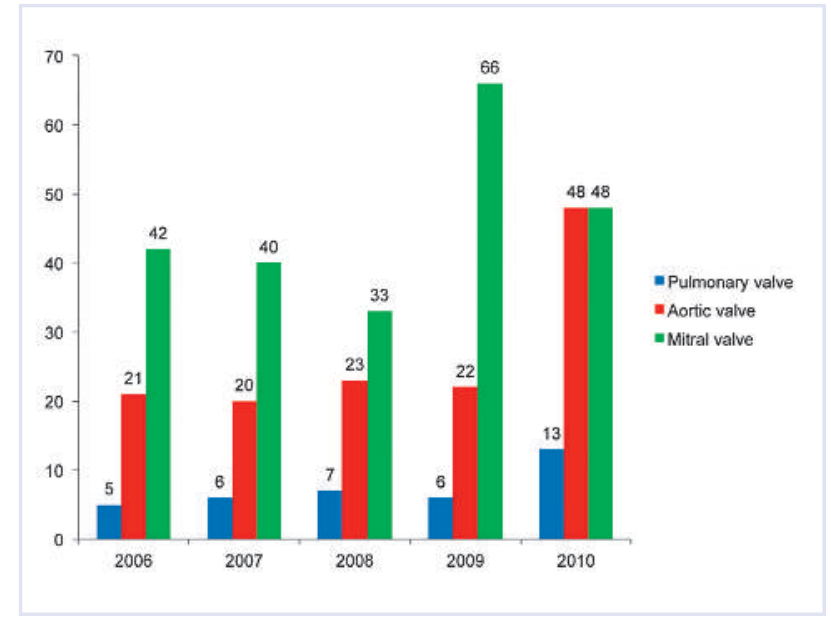

\section{Figure 6}

Interventions for structural heart defects: closure of atrial septal defect (ASD) and patent foramen ovale (PFO), transcatheter aortic valve implantation (TAVI), and transcatheter mitral valve repair (TMVR) from 2006 to 2010 .

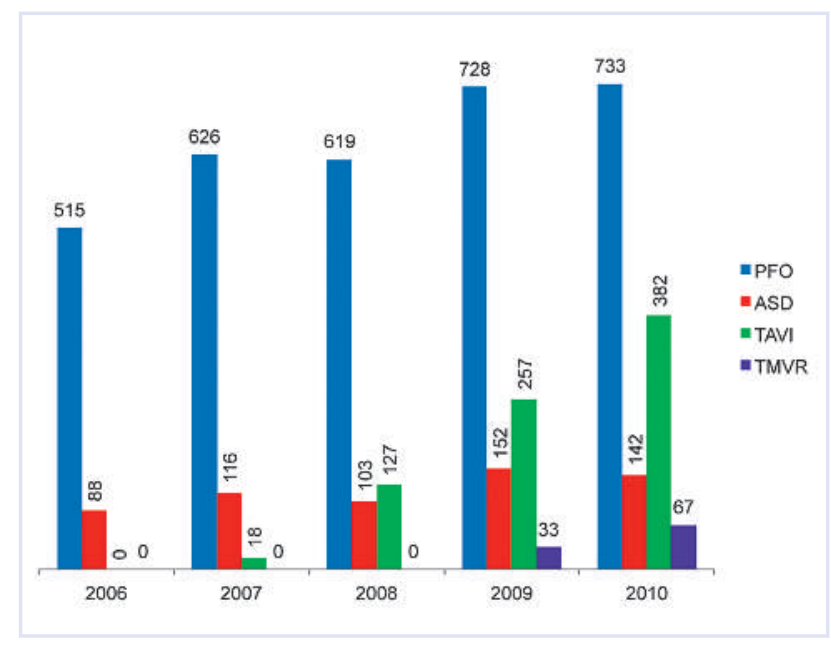

proportion of DES increased significantly in 2010 after a decrease from 2006 to 2007 and a plateau between 2007 and 2009. The proportion of DES varied considerably among different centres ranging from $53 \%$ to $97 \%$.

\section{$\mathrm{PCl}$ for acute myocardial infarction}

Emergency interventions in patients with ST-segment elevation myocardial infarction (STEMI; primary PCI or rescue PCI after failed thrombolysis) accounted for $20 \%$ of PCI procedures in 2010 (data not available from one centre; 2009: 20\%). In 2010, 27 out of 28 (96\%) centres reported PCI for STEMI (no information available for one centre). Percutaneous coronary intervention for cardiogenic shock accounted for $2.0 \%$ of PCI in 2010 (data not available from three centres; 2009: 1.8\%). In 2010, intra-aortic balloon pumps were used in 480 (2009: $\mathrm{n}=477)$ cases and a total of $67(2009: \mathrm{n}=47)$ percutaneous left ventricular assist devices were implanted. Glycoprotein IIb/IIIa inhibitors were used in 13\% (data not available from one centre; 2009: 17\%). As shown in figure 4, the utilisation of glycoprotein IIb/ IIIa inhibitors clearly decreased over the last years.

\section{Adjunctive techniques and special interventions}

Distal protection devices were used in $1.6 \%$ of PCI cases in 2010 (data not available from one centre; 2009: 1.9\%). An intracoronary pressure wire was employed in 5.7\% of cases in 2010 (2009: 4.2\%). Intravascular ultrasound was performed in $4.6 \%$ of PCI (2009: $5.0 \%$ ). Revascularisation techniques other than balloon angioplasty included rotablation $(\mathrm{n}=95 ; 2009$ : $\mathrm{n}=76$ ) and atherectomy $(\mathrm{n}=83 ; 2009: \mathrm{n}=28)$. Alcohol ablation of septal hypertrophy was performed in 37 patients (2009: $\mathrm{n}=38)$.

\section{Vascular access and management of puncture site}

The femoral artery was the most commonly used access site (85\%; data not available from one centre; 2009 : 85\%). Approaches other than the femoral artery were more popular in the French speaking part of Switzerland (43\% non-femoral approach, 2009: 32\%) compared to the Swiss German part and Ticino (4\% non-femoral approach, 2009: 6\% non-femoral approach). Information on the management of the puncture site was difficult to interpret because reporting was not uniform. In the centres proving information on the management of the puncture site per number of CA ( $48 \%$ of which were followed by PCI), manual compression was used in $37 \%$, collagen-based devices were used in $33 \%$, and suture-based devices in $30 \%$. In centres reporting figures per PCI, closure devices (approximately 50\% collagenbased, 50\% suture-based) were used in the vast majority of cases (approximately 90\%) if a femoral access site was used. 


\section{Non-coronary interventions}

With respect to balloon valvuloplasties, there was an increase in 2010 compared with previous years (fig. 5). In the third year after its introduction in Switzerland, there was another marked increase in TAVI procedures (fig. 6). While TAVI was performed in only one centre in 2007, in seven centres in 2008, and in eight centres in 2009, TAVI was offered in eleven centres in 2010. In 2010, the majority of valves were transfemoral implants $(\mathrm{n}=298)$, but there was also a considerable number of transapical $(n=81)$ procedures, while the trans-subclavian approach $(n=3)$ was rarely used. In the second year of its use in Switzerland, the number of TMVR procedures more than doubled ( $\mathrm{n}=67$ in four centres; 2009: 33).

While overall the numbers of procedures for patent foramen ovale (PFO) and atrial septal defect (ASD) closure increased over the last five years, they levelled off between 2009 and 2010 (fig. 6).

\section{Discussion}

The 2010 survey on the practice of interventional cardiology in Switzerland revealed the following three main findings: firstly, the numbers of both CA and PCI continued to increase; secondly, the proportion of DES increased substantially compared to the previous three years; and thirdly, TAVI has been rapidly adopted.

The ongoing increase in the number of CA is remarkable, and there are several possible reasons for this as discussed in our last report [2] including the more frequent use of non-invasive tests with a high sensitivity for the detection of inducible myocardial ischaemia and the more frequent application of computed tomography coronary angiography, which on the one hand detects coronary artery disease (CAD) and triggers $\mathrm{CA}$ and on the other hand is associated with a relevant proportion of false positive findings. However, the fact that not only the number of CA but also the number of PCI and even the $\mathrm{PCI} / \mathrm{CA}$ ratio increased speaks against a more liberal indication for CA. We have to acknowledge that the interpretation of the PCI/CA ratio as an indicator for the proportion of patients with significant angiographic findings is hampered by the fact that the number of coronary bypass surgeries during this time period is not available. It is however unlikely that the practice to refer patients for surgery has significantly changed in 2010 (i.e., that less patients were referred for surgery in 2010). Finally, it is also possible that given the ageing of the population the prevalence of significant CAD is in fact rising in Switzerland and thereby contributing to a higher number of CA and PCI.

The high (Austria in 2009: 39\% [4], Germany in 2009: $36 \%$ [5]) and stable PCI/CA ratio also indicates that the practice to proceed to PCI after CA was not significantly affected by the COURAGE trial [6] and other studies comparing optimal medical treatment with PCI.
This may have been due to the fact that, on the one hand, PCI is a highly effective method for alleviating angina in many patients and that on the other hand the relevance of the COURAGE trial has been questioned not only because of the selected population studied but also because the follow-up time may have been too short [7]. Notably, the most recent guidelines on myocardial revascularisation published in 2010 [8] give a preference to surgical revascularisation in multi-vessel disease. Whether and how this will affect the practice of coronary revascularisation in Switzerland remains to be determined.

Similarly to previous years, stent implantation was performed during the vast majority of PCI in 2010. After a decrease in the proportion of DES from 2006 to 2007, most likely as a result of concerns regarding the safety of first generation DES [9], DES utilisation has remained stable until 2009, while in 2010 a marked increase was observed. This is most likely the result of consistent findings of studies highlighting the efficacy and safety of newer generation DES [10, 11], even in patients with acute myocardial infarction [12].

There were some other trends with regards to CA and PCI. Firstly, a substantial number of CA and PCI are now performed by a non-femoral (i.e., radial) approach. Interestingly, the radial approach is much more popular in the French speaking part of Switzerland. Secondly, the use of pressure wires for the measurement of the fractional flow reserve seems to be increasingly popular, probably as a result of the FAME study [13]. Thirdly, there seems to be a certain revival of rotablation procedures for heavily calcified lesions.

There is a strong trend towards more transcatheter procedures for structural heart disease. After its introduction in Switzerland in 2007, the use of TAVI has increased rapidly in the country. The adoption of TAVI reflects an unmet need of patients with severe symptomatic aortic stenosis deemed at increased risk of conventional surgical aortic valve replacement. The use of TAVI in these patients is supported by the recent result from the PARTNER trial (PARTNER A) [14]. Given that up to one third of patients with severe aortic stenosis are not being referred for surgery because of a high peri-operative risk, and in these patients the PARTNER (PARTNER B) [15] trial has shown a dramatic benefit in patients undergoing TAVI compared to those undergoing standard treatment (balloon valvuloplasty in many cases), further expansion of TAVI can be expected. Ongoing randomised trials (e.g., SURTAVI) will investigate whether it is appropriate to expand the indication for TAVI to patients at standard surgical risk.

Furthermore, TMVR was introduced in Switzerland in 2009 [16], and the number of procedures has more than doubled in 2010. Almost the totality of the procedures included the Mitra-Clip ${ }^{\mathrm{TM}}$ device, while a worldwide programme of percutaneous annuloplasty was abandoned due to a late complication of a device reported in on Swiss centre [17]. 
With respect to the Mitra-Clip ${ }^{\mathrm{TM}}$, the recently published EVERST II trial suggested that TMVR is an acceptable alternative to surgery for the treatment of patients with severe mitral regurgitation [18]. However, this study included unselected patients with severe mitral regurgitation, whereas in current practice TMVR is typically used as an option to alleviate severe MR in very sick patients deemed at high risk for surgery. Currently, the ideal patient for TMVR has not been defined yet, and additional data on the role of TMVR are needed.

The number of procedures for PFO and ASD rose substantially during the last five years but levelled-off in 2010. Results of ongoing prospective randomised trials comparing PFO closure with medical therapy for cryptogenic stroke prevention are still eagerly awaited and will hopefully better define the role of PFO closure in the near future [19].

\section{Limitations of the study}

A questionnaire-based survey has a number of limitations. Data reporting was incomplete with respect to several items, and some centres were not prepared to present all of the data of interest. Accordingly, results must be interpreted with caution. Given that information about indications for CA was not available and that the number of coronary bypass surgery procedures is not known, some aspects of the discussion remain speculative. In addition, we are unable to present data on complications as there is no event adjudication committee and a systematic assessment of complications during and following CA and PCI is not part of a routine process in many centres.

\section{Conclusions}

The number of both CA and PCI procedures further increased in 2010 in Switzerland. Percutaneous interventions for structural heart disease are expanding. In particular, TAVI has been rapidly adopted in Switzerland, and TMVR is currently performed with increasing frequency.

\section{References}

1 Meier B. Örtliche Entwicklung der Koronarangioplastie. Schweiz Med Wochenschr. 1989;119:1033-9.

2 Maeder MT, Windecker S, Pedrazzini G, Roffi M, Kaiser CA, Stauffer JC, et al. Interventional cardiology in Switzerland during the years 2008 and 2009. Cardiovascular Medicine. 2010;13:370-4.

3 Maeder MT, Windecker S, Roffi M, Kaiser CA, Stauffer JC, Pedrazzini G, et al. Interventional cardiology in Switzerland during the year 2007. Cardiovascular Medicine. 2010;13:18-24.

4 Mühlberger V, Pachinger O. Herzkathetereingriffe in Österreich im Jahr 2008 (mit Audit 2004 bis 2009). J Kardiol. 2010;17:1-18.

5 Bruckenberger E, Herausgeber. Herzbericht 2008 mit Transplantationschirurgie. Hannover: Eigenverlag Dr. Bruckenberger, 2009.

6 Boden WE, O'Rourke RA, Teo KK, Hartigan PM, Maron DJ, Kostuk WJ, et al.; COURAGE Trial Research Group. Optimal medical therapy with or without PCI for stable coronary disease. N Engl J Med. 2007;356:1503-16.

7 Meier B. Switzerland reports "courant normal" in interventional cardiology, 30 years after inventing it. Kardiovaskuläre Medizin. 2010;13:3-5.

8 European Association for Percutaneous Cardiovascular Interventions, Wijns W, Kolh P, Danchin N, Di Mario C, Falk V, Folliguet T, et al.; ESC Committee for Practice Guidelines. Guidelines on myocardial revascularization: The Task Force on Myocardial Revascularization of the European Society of Cardiology (ESC) and the European Association for Cardio-Thoracic Surgery (EACTS). Eur Heart J. 2010;31:2501-55.

9 Pfisterer M, Brunner-La Rocca HP, Buser PT, Rickenbacher P, Hunziker P, Mueller C, et al. Late clinical events after clopidogrel discontinuation may limit the benefit of drug-eluting stents: an observational study of drug-eluting versus bare-metal stents. J Am Coll Cardiol. 2006;48:2584-91.

10 Kedhi E, Joesoef KS, McFadden E, Wassing J, van Mieghem C, Goedhart D, Smits PC. Second-generation everolimus-eluting and paclitaxel-eluting stents in real-life practice (COMPARE): a randomised trial. Lancet. 2010;375:201-9.

11 Räber L, Jüni P, Nüesch E, Kalesan B, Wenaweser P, Moschovitis A, et al. Long-term comparison of everolimus-eluting and sirolimus-eluting stents for coronary revascularization. J Am Coll Cardiol. 2011;57:2143-51.

12 Räber L, Windecker S. Primary percutaneous coronary intervention and risk of stent thrombosis. A look beyond the HORIZON. Circulation. 2011;123: $1709-12$.

13 Tonino PA, De Bruyne B, Pijls NH, Siebert U, Ikeno F, van't Veer M, et al.; FAME Study Investigators. Fractional flow reserve versus angiography for guiding percutaneous coronary intervention. N Engl J Med. 2009;360; 213-24.

14 Smith CR, Leon MB, Mack MJ, Miller DC, Moses JW, Svensson LG, Tuzcu EM, et al.; PARTNER Trial Investigators. Transcatheter versus surgical aortic-valve replacement in high risk patients. N Engl J Med. 2011;364: 2187-98.

15 Leon MB, Smith CR, Mack M, Miller DC, Moses JW, Svensson LG, et al. Transcatheter aortic-valve implantation for patients who cannot undergo surgery. N Engl J Med. 2010;363:1597-607.

16 Pedrazzini G, Sürder D, Mocchetti M, Hürlimann D, Faletra F, Felix C, et al. Perkutane Katheter-basierte Behandlung der schwere Mitralinsuffizienz. Erste Schweizer Erfahrung mit dem MitraClip-System. Cardiovasc Med. 2010;13:122-9.

17 Noble S, Vilarino R, Muller H, Sunthorn H, Roffi M. Fatal coronary sinus and aortic erosions following percutaneous transvenous mitral annuloplasty device. EuroIntervention. 2011;7:148-50.

18 Feldman T, Foster E, Glower DG, Kar S, Rinaldi MJ, Fail PS, et al.; EVEREST II Investigators. Percutaneous repair or surgery for mitral regurgitation. N Engl J Med. 2011;364:1395-406.

19 O'Gara PT, Messe SR, Tuzcu EM, Catha G, Ring JC. Percutaneous device closure of patent foramen ovale for secondary stroke prevention. A call for completion of randomized clinical trials. A science advisory from the American Heart Association/American Stroke Association and American College of Cardiology Foundation. Circulation. 2009;119:2743-7.

\section{Appendix / local coordinators}

Aarau Kantonsspital:

Aarau Hirslanden Klinik:

Basel Universitätsspital:

Basel Claraspital:

Bern Inselspital/Klinik Sonnenhof:

Bern Klinik Beau-Site:

Bern Tiefenauspital:

Bern Lindenhofspital:

Biel Spitalzentrum:

Chur Kantonsspital:

Fribourg Kantonsspital:

Genève Clinique des Grangettes:

Genève Hôpitaux Universitaires:

Genolier Clinique:

Kreuzlingen Herzzentrum Bodensee:

Lausanne Clinique de la Source:

Lausanne Clinique Cecil:

Lausanne Centre Hospitalier Universitaire Vaudois:

Lugano Cardiocentro:

Luzern Kantonsspital:

Luzern Klinik St. Anna:

Meyrin Hôpital La Tour:

Sion Hôpital Régional:

Sion Clinique de Valère:

St. Gallen Kantonsspital:

Zürich Hirslanden-Kliniken:

Zürich Triemli Stadtspital:

Zürich Universitätsspital /

Kantonsspital Winterthur /

Spital AG Thurgau (Frauenfeld):
A. Vuilliomenet

C. Neuenschwander

C. Kaiser

B. Hornig

P. Wenaweser

C. Noti

M. Brack

A. Garachemani

C. Röthlisberger

P. Müller

S. Cook

P. Chatelain

P.A. Dorsaz

V. Verin

M. Pieper

G. Rouvinez

A. Berger

C. Roguelov

G. Pedrazzini

P. Erne

T. Chatterjee

P. Urban

G. Girod

C. Imsand

D. Weilenmann

E. Schuiki/

F.W. Amann

F. Eberli

W. Maier 